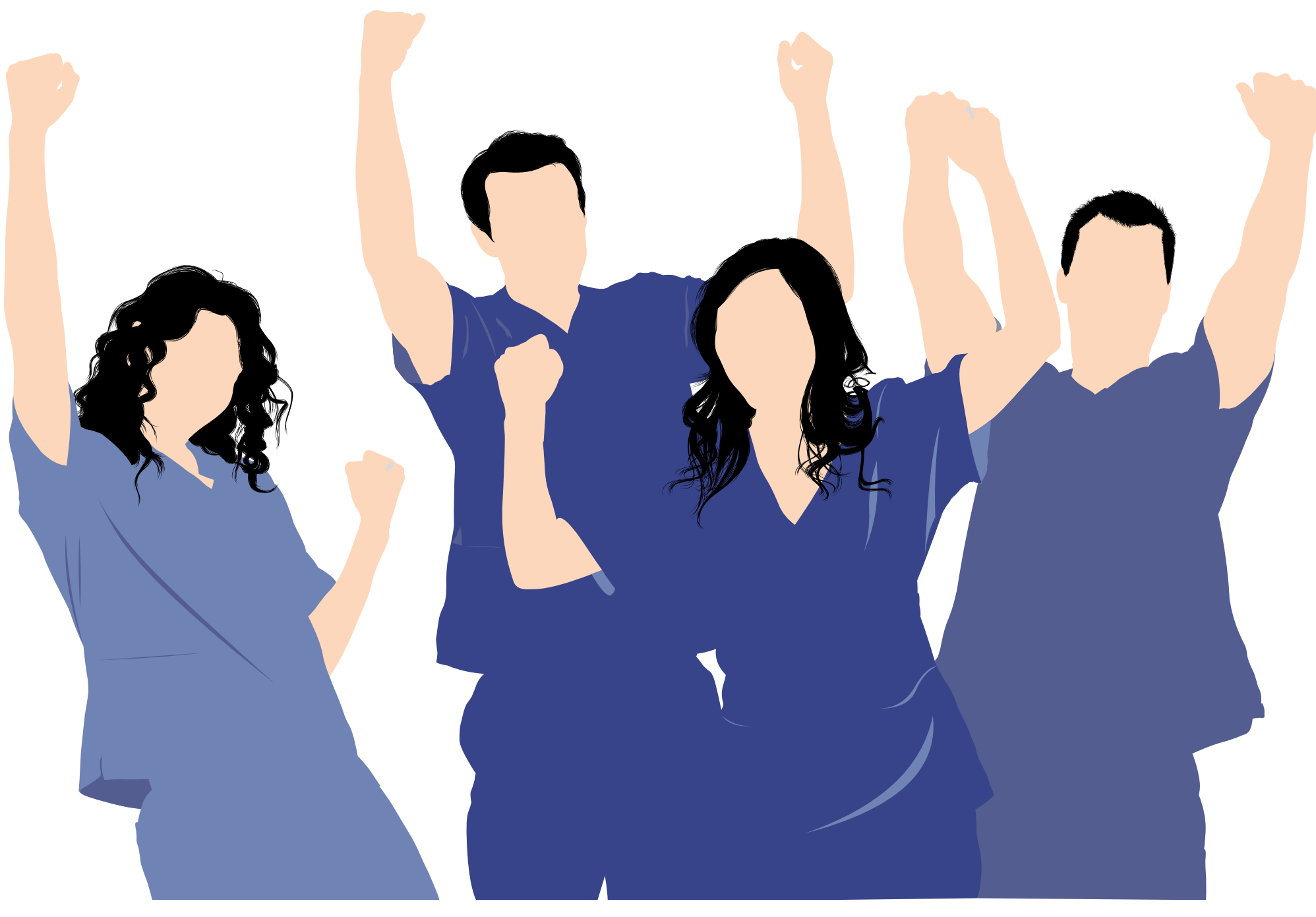

\title{
'We celebrate those who got the profession to this point"
}

Fiona Ellwood' provides an update on the activities of the Society of British Dental Nurses (SBDN) in 2021.

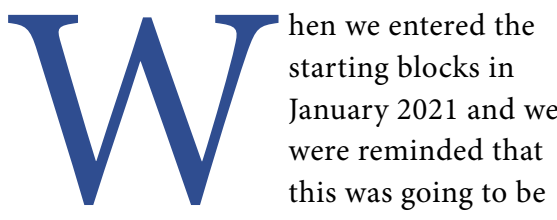

a marathon not a sprint, I strongly believe that none of us truly knew how 2021 would play out, but here we are about to reach the finish line and another year of living with the impact of the pandemic will soon be gone.
The Society of British Dental Nurses (SBDN) has certainly had a bumper year and a year of thinking outside of the box, with lots to celebrate. One thing for sure is that we have continued to support our members and others along the way and the heart-warming thing is that we are finally seeing some strong relationships building and partnerships in our plans for 2022.

The team have been so busy, despite all being volunteers and being active in the field.
We have a new generation of dental nurses bringing ideas to the table and we hope to introduce you to many of them soon. SBDN have a buddy system, so that corporate knowledge and expertise is not lost and that often sits hand in hand with our mentorship work.

We are delighted to say this year we have new ambassadors in all four nations and the international arm is growing too. Looking back on 2021 and the goals we set and the 
hopes we had, I don't think many of the team will be disappointed.

\section{What did we get up to in 2021 ?}

Like many others we have used our time well. We have put a lot of energy into designing our hubs and special interest groups and already they are making a difference. The following list may well help you to see where we have been and perhaps some of aspirations for 2022.

- SBDN have attended a number of stakeholder meetings in broad discussions about responding to COVID-19

- We have responded to a number of consultations, some from the regulators

- We have attended meetings with Chief Dental Officers and some education providers and awarding bodies

- We have been involved in webinars held by the profession and were privileged to present our work on the 'Mouse in the House', following on from Nishma Sharma's work on racism [see https://www. nature.com/articles/s41407-021-0669-x]

- As part of the Dental Professional Alliance (DPA), SBDN have been involved in the Mental Health Wellness in Dentistry initiative [see https://www.nature.com/ articles/s41407-021-0640-x]

- With the International Coalition for Community Oral Health we have presented at COP26 on climate change and inequalities

\section{Author information}

'Fiona is the President and Executive Director of the Society of British Dental Nurses, a member of the Dental Professional Alliance (DPA) and a BDJ Team reader panellist. She has received a British Empire Medal (BEM) and acts as a key opinion leader and advisor for oral health and preventative practice, infection prevention and professional practice. She has a strong interest in population level health matters and inequalities in health. Fiona is heavily involved in education across the sector and invests a great deal of time on programme design and development with a strong focus on quality assurance and assessment.
- SBDN have also been one of the founding groups behind the formation of the International Federation of Dental Assistants and Dental Nurses (https:// ifdan.org/). Through this group we are able to share experiences and research and support each other across the miles. This also created an opportunity to present the mental health work, the 'Mouse in the House' work and of course the work by Nishma and the team on equality, diversity and inclusion within dentistry

- We also had a seat on the panel of 'balance the boards' (https:// balancethedentalboards.com/); of course dental nursing is predominantly female, so we were on the opposite side of the fence. We did add another dimension though by
This is simply a snapshot of what has been going on at the Society, but I am sure you will agree it has been very busy. Our help and support lines are still in demand and sadly, there are people out there still finding life daunting. Those that perhaps feel stronger could change someone's day by leaning in.

We cannot help but be concerned about the dental nursing workforce challenges. They are nothing new, but the pandemic has certainly added to the challenges. We have a strong eye on education in dental nursing and cannot help being concerned on that front too; we would like to see something positive come from the fantastic work and commitment that dental nurses have shown over the last two years and a scoping exercise on 'workforce in and workforce out'.

\section{'I strongly believe that none of us truly}

knew how 2021 would play out, but

here we are about to reach the finish line and another year of living with the pandemic will soon be gone.'

asking that boards considered the whole team and didn't judge by registration

- The student safe space was launched; our first speaker came from the GDC and it seems to have been a real hit

- We have made changes to our journal too, The Dental Nursing Times; it needed an update and it has certainly had that

- We mustn't forget to introduce our new Patron Mili Doshi and two new additions to our Honorary Fellows Board, Professor Avi Banerjee and Dr Tripat Mahajan, along with a number of new ambassadors

- 2020 was a first big milestone for SBDN and really 2021 was year one of our next five year strategy. We also introduced the SBDN Excellence programme and published our latest version of the 'Post Nominals and Membership Credentials' and the new Indemnity Scheme

- Like many, we were invited to the launch of the new College of General Dentistry and on a personal level I presented at the British Fluoridation Society event recently.
As the current President, some may say what a time to be President, but I have to say it has been an honour and a privilege and I am looking forward to the succession planning meeting next month. In the meantime, we have not long celebrated the Professor Ireland Annual Lecture with excellent speakers as always; we have the annual conference firmly in view (20 November) and of course the National Dental Nurses Day on 22 November, which marks the first dental nursing examination of 1943 in the UK.

So, what for 2022 ? We will know soon enough, with the AGM round the corner, exciting opportunities already presenting themselves and new partners on board. Whatever it looks like, our membership is central to our work, as are dental nurses, and we celebrate those who got the profession to this point and those who will take it forward, because dental nurses matter too.

https://doi.org/10.1038/s41407-021-0775-9 